\title{
Inter- and Intraobserver Variability of 99mTc-DMSA Renal Scintigraphy: Impact of Oblique Views
}

\author{
Meltem Caglar ${ }^{1}$, Pınar Özgen Kıratl1 ${ }^{1}$, and Erdem Karabulut ${ }^{2}$ \\ ${ }^{I}$ Department of Nuclear Medicine, Hacettepe University, Ankara, Turkey; and ${ }^{2}$ Department of Biostatistics, Hacettepe University, \\ Ankara, Turkey
}

\begin{abstract}
99mTc-Dimercaptosuccinic acid (DMSA) scintigraphy is a frequently used diagnostic test to assess the presence and severity of cortical damage. The aim of this study is to investigate the variability in the interpretation of $99 \mathrm{mTc}$-DMSA scans, evaluate the usefulness of oblique images, and assess their impact on scan interpretation. Methods: Two experienced nuclear medicine physicians independently interpreted 100 99mTc-DMSA scans (197 kidneys) 4 times. Interpretation was twice based on posterior projection images and twice based on posterior and posterior oblique projection images. For each kidney, the observers had to choose between the following results: normal, abnormal, and indeterminate. The indices of variability used were the percentage of agreement, $\kappa$-statistic, and marginal homogeneity. Results: Intraobserver and interobserver reproducibility ( $\kappa$-values) varied between 0.683 and 0.708 and between 0.609 and 0.671 , respectively, for posterior images. Disagreement in $99 \mathrm{mTc}$ DMSA scan interpretation occurred in $18 \%$ of kidneys within observers and in $21 \%$ of kidneys between observers when only posterior images were used. Oblique views changed the interpretation in $14 \%$ and $11.5 \%$ of kidneys for the first and second observers, respectively. The use of oblique views increased the agreement rate within and between observers ( $\kappa$-values, $0.725-0.812$ and $0.768-0.732$, respectively; mean agreement, 86.5 and 87.25 , respectively). Conclusion: Oblique views were found useful in approximately $13 \%$ of kidneys and affected interand intraobserver variability. Our results suggest that oblique views should be used routinely in children with clinically suspected urinary tract infection to reliably interpret images.
\end{abstract}

Key Words: DMSA; scintigraphy; observer variability

J Nucl Med Technol 2007; 35:96-99

DOI: 10.2967/jnmt.106.036111

$\mathbf{S}$ cintigraphy with ${ }^{99 \mathrm{~m} T c-d i m e r c a p t o s u c c i n i c}$ acid (DMSA) is used to identify children who have renal cortical damage, and clinical decisions are often influenced by the scan results (1-5). Although procedure guidelines suggest that optimal

Received Aug. 27, 2006; revision accepted Feb. 12, 2007.

For correspondence contact: Meltem Caglar, MD, Department of Nuclear Medicine, Hacettepe University, Sihhiye, Ankara, 06100, Turkey.

E-mail: mcaglar@hacettepe.edu.tr

COPYRIGHT @ 2007 by the Society of Nuclear Medicine, Inc. imaging should include right and left posterior oblique views in addition to posterior images, the utility of oblique views has been questioned (o). There are also not enough reliable data in the literature on the utility of oblique views in the interpretation of scintigraphic reports.

This work was undertaken to evaluate the level of interand intraobserver variability in ${ }^{99 \mathrm{~m}} \mathrm{Tc}-\mathrm{DMSA}$ scintigraphy and to identify the impact of posterior oblique views on scan interpretation in the pediatric population.

\section{MATERIALS AND METHODS}

A total of 197 kidneys, which were randomly selected from our database, were retrospectively evaluated. Patient age varied between 3 mo and $17 \mathrm{y}$. All scans were displayed on gray-scale, clear-based, hard-copy radiographic films. Static renal scintigraphy was performed $3 \mathrm{~h}$ after the administration of ${ }^{99 \mathrm{~m}} \mathrm{Tc}-\mathrm{DMSA}$. The dose was scaled on a body weight basis using an adult dose of $185 \mathrm{MBq}(5 \mathrm{mCi})$ (range, 37-185 MBq [1-5 mCi]). Scintigraphic images $(128 \times 128$ matrix) were acquired over 5 min from posterior and posterior oblique projections using a $\gamma$-camera equipped with a high-resolution collimator and using a 1.23 zoom factor.

Patients with congenital malformations, renal failure, and lowquality images were excluded from the study.

All films were viewed by 2 experienced nuclear medicine specialists. Apart from being informed that urinary tract infection was the indication for ${ }^{99 \mathrm{~m}} \mathrm{Tc}-\mathrm{DMSA}$ scintigraphy, the nuclear medicine physicians were given no other clinical information. Films were read on 4 separate occasions-all independently to ensure that no bias was introduced. The first interpretation was based on the posterior images. The second was based on both the posterior and the posterior oblique images. The third, 2 wk later, was a reinterpretation of the same cases in the same sequence. Images were classified as normal, abnormal, or indeterminate (Figs. 1-3). ${ }^{99 \mathrm{~m}} \mathrm{Tc}$-DMSA scan findings were defined as abnormal if a defect in renal contour or an area of photon deficiency was present in the renal cortex.

Variability in the interpretation of 197 kidneys was assessed from the readings of 2 nuclear medicine physicians. The percentage of agreement and $\kappa$-statistics were used to measure inter- and intraobserver variability. In all calculations, reproducibility was estimated on the basis of complete agreement between observers where the number of possible answers was 3 (normal, abnormal, and indeterminate). The percentage of agreement was defined as 


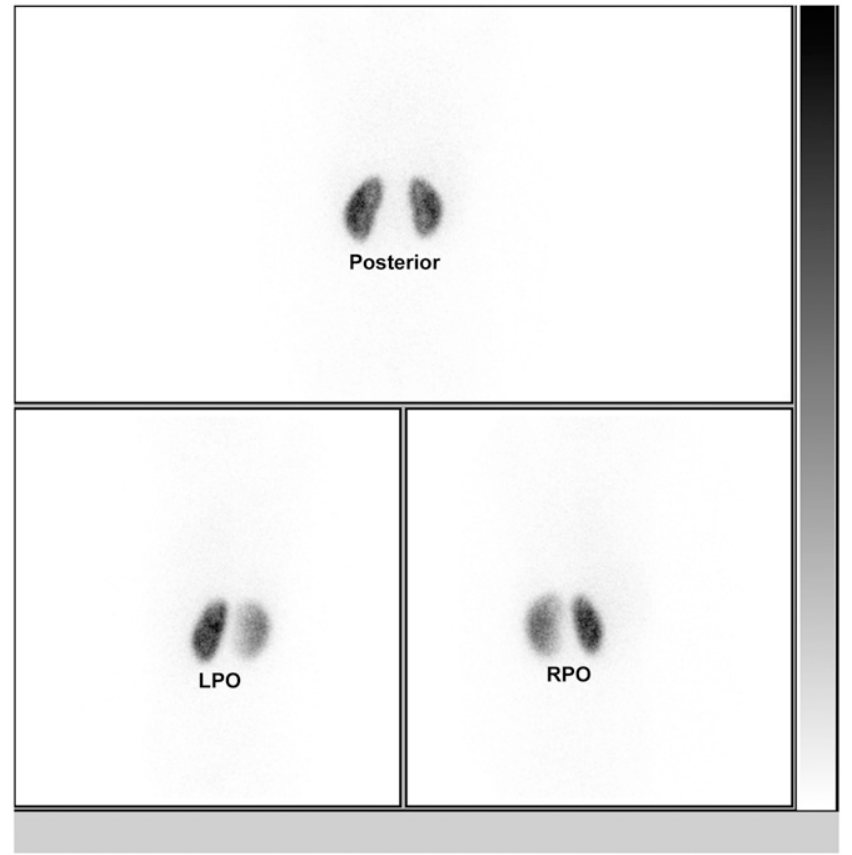

FIGURE 1. Normal findings on planar ${ }^{99 m}$ Tc-DMSA scintigraphy. $\mathrm{LPO}=$ left posterior oblique; RPO = right posterior oblique.

an index that gave a good measure of how well any posterior distribution agreed with the prior distribution. This rather simple statistic has the merit of being easy to understand. A measure generally thought to be more robust than the simple percentage

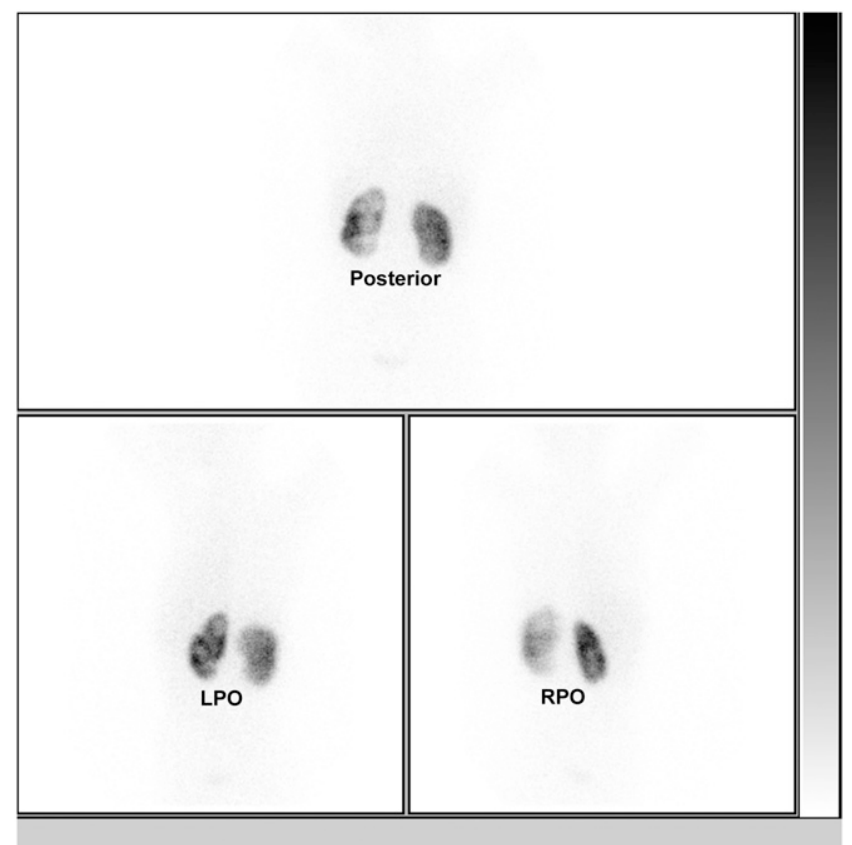

FIGURE 2. Abnormal findings on ${ }^{99 m} \mathrm{Tc}-\mathrm{DMSA}$ scintigraphy. Posterior, left posterior oblique (LPO), and right posterior oblique (RPO) images reveal slight enlargement of left kidney, with cortical defects. Although right kidney appears normal on posterior image, cortical defect is seen in lower pole on RPO view.

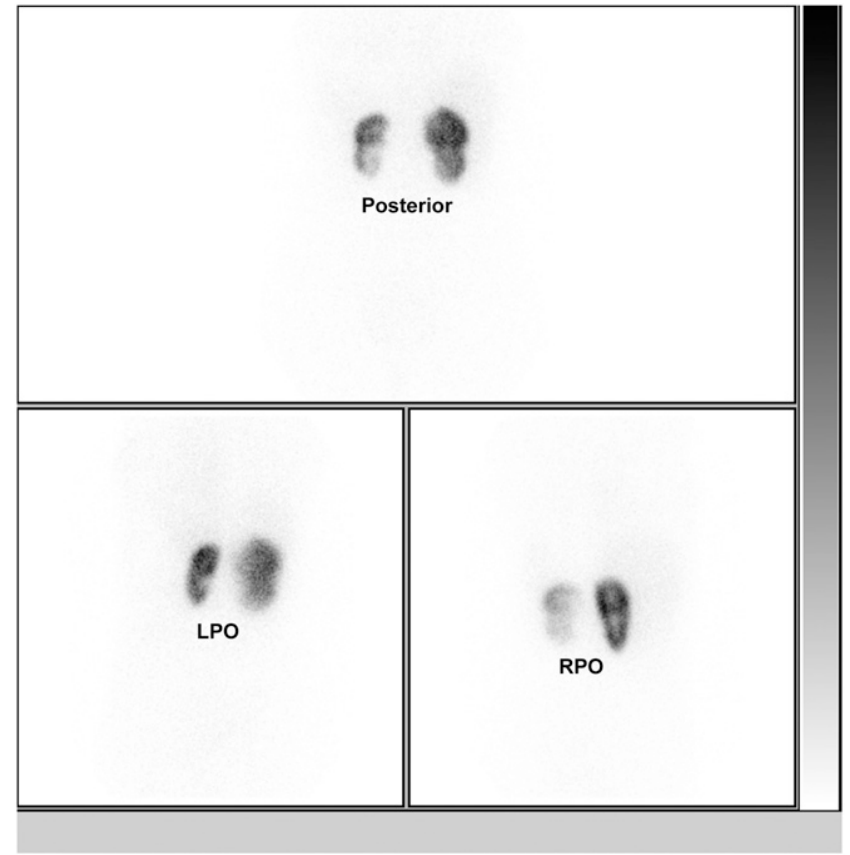

FIGURE 3. 99mTc-DMSA scintigraphy showing small left kidney with parenchymal scarring. Right side is considered indeterminate on posterior and posterior oblique views because of midzone impression seen in upper pole-lower pole junction suggestive of duplex kidney. Because no evidence of duplex kidney was present, right kidney was considered indeterminate for acute pyelonephritis or cortical scar. LPO = left posterior oblique; RPO = right posterior oblique.

agreement calculation is Cohen's k-coefficient (7), because it adjusts for agreement attributable to chance and can range from -1 to +1 , the latter representing perfect agreement. The $\kappa$-statistic was used to measure interobserver variability (inconsistency of interpretation among different physicians) and intraobserver variability (the failure of a physician to be consistent in independent readings of the same scan). In practical terms, values above 0.61 were taken to indicate a high standard of agreement and a level at which the data could be accepted as reproducible (8).

Scan results were compared using a marginal homogeneity test for matched pairs. A $P$ value of less than 0.05 was considered significant.

\section{RESULTS}

Table 1 shows the results given by 2 observers for 197 kidneys. Adding oblique images changed the results for the first and second observers in 32 kidneys (16\%) and 27 kidneys (14\%), respectively, in the first interpretation and in 24 kidneys (12\%) and 20 kidneys $(10 \%)$, respectively, in the second interpretation. The proportion of indeterminate results was significantly reduced when oblique images were used for interpretation $(P=0.023, P=000, P=0.036)$, except for the second observer in the second interpretation $(P=0.307)$.

The $\kappa$-statistics for inter- and intraobserver variability is given in Tables 2 and 3. The reproducibility of image 
TABLE 1

Impact of Oblique Images for DMSA Scan Interpretation

\begin{tabular}{|c|c|c|c|c|}
\hline \multirow[b]{2}{*}{ Interpretation } & \multicolumn{2}{|c|}{ Posterior } & \multicolumn{2}{|c|}{ Posterior and oblique } \\
\hline & Observer 1 & Observer 2 & Observer 1 & Observer 2 \\
\hline \multicolumn{5}{|l|}{ First reading } \\
\hline Normal & 86 (43.7\%) & 78 (39.6\%) & 98 (49.7\%) & 102 (51.8\%) \\
\hline Indeterminate & 19 (9.6\%) & $28(14.2 \%)$ & $6(3 \%)$ & $4(2 \%)$ \\
\hline Abnormal & $92(46.7 \%)$ & $91(46.2 \%)$ & 93 (47.3\%) & $91(46.2 \%)$ \\
\hline Total & 197 (100\%) & 197 (100\%) & 197 (100\%) & 197 (100\%) \\
\hline \multicolumn{5}{|l|}{ Second reading } \\
\hline Normal & 77 (39.1\%) & 78 (39.6\%) & 87 (44.2\%) & $83(42.1 \%)$ \\
\hline Indeterminate & 25 (12.7\%) & $18(9.1 \%)$ & $13(6.6 \%)$ & $12(6.1 \%)$ \\
\hline Abnormal & $95(48.2 \%)$ & $101(51.3 \%)$ & $97(49.2 \%)$ & $102(51.8 \%)$ \\
\hline Total & $197(100 \%)$ & $197(100 \%)$ & 197 (100\%) & $197(100 \%)$ \\
\hline
\end{tabular}

interpretation was good and was slightly better when posterior oblique images were used. When only posterior images were used, complete agreement was achieved in 151 kidneys $(77 \%)(\kappa=0.609)$ in the first interpretation and in 159 kidneys $(81 \%)(\kappa=0.671)$ in the second. When both the posterior and the posterior oblique views were used, complete agreement was achieved in 173 kidneys $(88 \%)(\kappa=0.768)$ and 167 kidneys $(85 \%)(\kappa=0.732)$ in the first and second interpretations, respectively.

\section{DISCUSSION}

Although renal cortical scintigraphy with ${ }^{99 \mathrm{~m} T c-D M S A}$ is widely used, primarily for the evaluation of renal parenchymal damage, conflicting opinions have been expressed about its reproducibility (9-13). Some investigators advocate the addition of pinhole images and SPECT (14); however, motion artifacts due to the long acquisition time may be a problem (15). Recent results demonstrated that highresolution planar imaging, pinhole imaging, and SPECT can provide similar results in demonstrating renal cortical defects (16).

This study demonstrated a high level of agreement in the interpretation of ${ }^{99 \mathrm{~m}} \mathrm{Tc}-\mathrm{DMSA}$ scans showing urinary tract infection. The $\kappa$-values varied between 0.683 and 0.708 for intraobserver variability and between 0.609 and 0.671 for interobserver variability, which was classified as good when only posterior views were used. With the addition of oblique projections, the $\kappa$-values improved slightly $(0.725-0.812$ and $0.768-0.732$, respectively). A higher level of intraobserver consistency suggested that observers are of clearer mind about the definition of renal parenchymal damage.
Oblique views, when used with posterior images, provide a firm basis for clinical decision making, especially in patients who have photon-deficient areas due to dilated calices or questionable contours. The interpretation of 99m Tc-DMSA scintigraphy from only the posterior view, compared with oblique views also, will underestimate the number of normal scans. This effect is relevant in patients with urinary tract infection, because a strategy to perform voiding cystourethrography in only patients with renal lesions has been proposed (5).

The degree of reproducibility may also depend on the severity and extent of lesions. Abnormalities seen during the acute phase of infection may be more striking and less challenging. In this study, the scans were randomly selected and represented the routine clinical workload. Areas of parenchymal damage appeared as hypoactive, with or without deformity of the contours. Difficulties remain in the interpretation of subtle cases and are related to the lack of an established definition for anatomic variants.

\section{CONCLUSION}

These results indicate that technically well-performed studies on a planar high-resolution collimator can yield valuable information in children with either clinically suspected acute pyelonephritis or renal scarring. In our series, at least $10 \%$ of patients with urinary tract infection could have been sent for voiding cystourethrography on the basis of equivocal ${ }^{99 \mathrm{~m}}$ Tc-DMSA results. Although this study was limited by the lack of a standard of reference against which to judge the performance of both views, our results indicated

TABLE 2

К-Statistics for Intraobserver Variability of DMSA Scintigraphy

\begin{tabular}{|c|c|c|c|c|c|c|}
\hline \multirow[b]{2}{*}{ Observer } & \multicolumn{2}{|r|}{$\kappa$-Value } & \multicolumn{2}{|c|}{ Standard error } & \multicolumn{2}{|c|}{ Probability of agreement } \\
\hline & Posterior & Posterior and oblique & Posterior & Posterior and oblique & Posterior & Posterior and oblique \\
\hline 1 & 0.708 & 0.812 & 0.043 & 0.038 & 82.7 & 89.3 \\
\hline 2 & 0.683 & 0.725 & 0.044 & 0.044 & 81.2 & 85.2 \\
\hline
\end{tabular}


TABLE 3

К-Statistics for Interobserver Variability of DMSA Scintigraphy

\begin{tabular}{|c|c|c|c|c|c|c|}
\hline \multirow[b]{2}{*}{ Views } & \multicolumn{2}{|c|}{ к-value } & \multicolumn{2}{|c|}{ Standard error } & \multicolumn{2}{|c|}{ Probability of agreement } \\
\hline & First reading & Second reading & First reading & Second reading & First reading & Second reading \\
\hline Posterior & 0.609 & 0.671 & 0.047 & 0.044 & 76.6 & 80.7 \\
\hline Posterior and oblique & 0.768 & 0.732 & 0.043 & 0.043 & 87.8 & 85.2 \\
\hline
\end{tabular}

that the lesions were more confidently diagnosed on oblique images.

\section{REFERENCES}

1. Gordon I. Indications for technetium-99m dimercaptosuccinic acid scan in children. J Urol. 1987;137:464-467.

2. Gleeson FV, Gordon I. Imaging in urinary tract infection. Arch Dis Child. 1991;66:1282-1283.

3. Goldraich NP, Goldraich IH. Update on dimercaptosuccinic acid renal scanning in children with urinary tract infection. Pediatr Nephrol. 1995;9:221-226.

4. Rushton HG. The evaluation of acute pyelonephritis and renal scarring with technetium 99m-dimercaptosuccinic acid renal scintigraphy: evolving concepts and future directions. Pediatr Nephrol. 1997;11:108-120.

5. Hansson S, Dhamey M, Sigström O, et al. Dimercaptosuccinic acid scintigraphy instead of voiding cystourethrography for infants with urinary tract infection. J Urol. 2004;172:1071-1074.

6. Mannes F, Bultynck E, Van Roijen N, Van Der Mauten L, Piepsz A, Ham H. Utility of posterior oblique views in Tc-99m DMSA renal scintigraphy. $\mathrm{J} \mathrm{Nucl}$ Med Technol. 2003;31:72-73.

7. Cohen JA. A coefficient of agreement for nominal scales. Educ Psychol Meas. 1960;20:37-46.

8. Brennan P, Silman A. Statistical methods for assessing observer variability in clinical measures. BMJ. 1992;304:1491-1494.
9. Piepsz A, Clarke SEM, Mackenzie R, Gordon I. A study on the interobserver variability in reporting on Tc-99m DMSA scintigraphy [abstract]. Eur J Nucl Med. 1993;20:194.

10. Patel K, Charron M, Hoberman A, Brown ML, Rogers KD. Intra- and interobserver variability in interpretation of DMSA scan using a set of standardized criteria. Pediatr Radiol. 1993;23:506-509.

11. Everaert H, Flamen P, Franken PR, Peeters P, Bossuyt A, Piepsz A. 99TcmDMSA renal scintigraphy for acute pyelonephritis in adults: planar and/or SPET imaging? Nucl Med Commun. 1996;17:884-889.

12. Gacinovic S, Buscombe J, Costa DC, Hilson A, Bomanji J. Ell PJ. Interobserver agreement in the interpretation of Tc-99m DMSA renal studies. Nucl Med Commun. 1996;17:596-602.

13. De Sadeleer C, Tondeur M, Melis K, et al. A multicenter trial on interobserver reproducibility in reporting on Tc-99m DMSA planar scintigraphy: a Belgian survey. J Nucl Med. 2000;41:23-26.

14. Tarkington MA, Fildes RD, Levin K, Zeissman H, Harkness B, Gibbons MD. High resolution single photon emission computerized tomography (SPECT) $99 \mathrm{~m}$ technetium-dimercapto-succinic acid renal imaging: a state of the art technique. J Urol. 1990;144:598-600.

15. Rossleigh M. Renal cortical scintigraphy and diuresis renography in infants and children. J Nucl Med. 2001;42:91-95.

16. Applegate K, Connolly L, Davis R, Zurakowski D, Treves ST. A prospective comparison of high-resolution planar, pinhole, and triple-detector SPECT for the detection of renal cortical defects. Clin Nucl Med. 1997;22: 673-678.

\section{Erratum}

In the article "Nuclear Medicine Technologists in the U.S.: Findings from a 2005 Survey" prepared by the Center for Health Workforce Studies (the Center) (JNMT. 2006;34:244-249), the data on states with the highest and lowest numbers of nuclear medicine technologists per 1,000,000 in population were incorrect. The sentence reporting the range should read, "At the high end of the spectrum were South Dakota (160), West Virginia (143), and Delaware (135), and at the low end were the District of Columbia (23), Kansas (36), and Idaho (38)." Nebraska was not near the top of the range, and Oklahoma and Nevada were not near the bottom. Oklahoma had 62 nuclear medicine technologists per million, and Nebraska had 78 per million. Nevada had a total of 180 nuclear medicine technologists at the time of the survey (77 per million). The Center regrets the errors. 